\title{
A revolução do processo: os afetos e o devir revolucionário
}

\author{
The process's revolution: the affects and the revolutionary devir
}

\section{Carolina Licks Carvalho}

Resumo: Este trabalho caminha pelas conversas sobre resistência, devir-revolucionário e os processos onde escapam as linhas duras de movimentos sociais. Junto das paralisações dos professores do Centro Universitário Metodista em abril e maio de 2018, um movimento estudantil construiu espaços de diferença em uma instituição endurecida e que vêm sofrendo desmanches significativos. Nesse sentido, os objetivos deste trabalho foram mapear os afetos que se engendraram dentro do movimento estudantil, cartografar as linhas de fuga e os devires revolucionários que deram vida a um espaço onde movimentos de luta não costumavam acontecer. Movendo-se por processos cartográficos e genealógicos, a metodologia dá-se por cartografar caminhos que escaparam, que fizeram fugir as linhas duras desse movimento estudantil. Nesse sentido, o texto se torna parte desse processo de resistência também. Ainda assim, é um trabalho feito com arte, criação e invenção; referenciada em uma escrita teatral; não se propõe a trazer grandes verdades nem conclusões; o texto é parte do encontro da autora com o movimento estudantil e com seu processo de escrita, dando vazão para os atravessamentos implicados. O movimento estudantil dentro do IPA construiu processos revolucionários - outros nem tanto -, fez-se grandioso por meios minoritários de resistência, tentou traçar também caminhos cristalizados de linhas duras e fez fugir pela diferença. A esse texto interessa o meio, o entre, a duração, pois, alinhado às perspectivas pós-estruturalistas, sobretudo à filosofia de Gilles Deleuze, Félix Guattari e Michel Foucault, a revolução não está no produto final, mas no processo.

Palavras-chave: Devir-revolucionário; Afetos; Resistência; Movimento estudantil; Cartografia.
Abstract:Thisworkgoesthroughtheconversations about resistance, revolutionary devir and the processes where the hard lines of social movements escape. Along with the paralyzes of the teachers of the Centro Universitário Metodista IPA, in April and May of 2018, a student movement make to construct spaces of difference in a hardened institution and that has been suffering significant disruptions. In this sense, the objectives of this work were to map the affections that were engendered within the student movement, to map the lines of scape and the revolutionary's devir that gave life to a space where fighting movements did not usually happen. Moving through cartographic and genealogical processes, the methodology is based on mapping out paths that have escaped the hard lines of this student movement. In this sense, the text becomes part of this process of resistance as well. Still, it is a work done with art, creation and invention; referenced in a theatrical writing; it does not propose to bring great truths or conclusions; the text is part of the author's encounter with the student movement and its writing process, giving vent to the involved crossings. The student movement within the IPA built revolutionary processes - others not so much -, made great by minority means of resistance, tried to also trace crystallized paths of hard lines and made escape by difference. This text concerns the medium, the between, the duration, because, aligned with the poststructuralist perspectives, especially the philosophy of Gilles Deleuze, Félix Guattari and Michel Foucault, the revolution is not in the final product, but in the process.

Keywords: Revolutionary devir; Affections; Resistance; Student movement; Cartography.

1 Graduanda em Psicologia pelo Centro Universitário Metodista - IPA. E-mail: carol.licks@gmail.com . 


\section{Prólogo}

Ao ler esse prólogo, tu irás perceber que ele pouco se parece com um prólogo. Assim como esse trabalho irá pouco se parecer com um trabalho de conclusão de curso. Tudo bem, explico-te logo sobre isso. É que os acontecimentos que serão cartografados, os devires revolucionários, as linhas de fuga e os afetos alegres que serão mapeados não dão conta de serem escritos nos modos acadêmicos mais comuns - até poderiam, mas confesso que não me interesso em simplificá-los às discussões puramente teóricas. Há de se usar da arte, de se criar algo novo, justamente porque a potência de toda duração - daquilo que se sente, não da quantidade tempo, como pontuado por Bergson - que tentarei traçar neste trabalho é muito sensivel para "apenas" elucidações intelectuais.

Desse modo, retifico então, que este será um trabalho escrito com arte, se propõe a ser parte do rizoma como "a grama: ela transborda de tanto ser sóbria. Ela brota entre: é o próprio caminho. "(Deleuze \& Guattari, 1995) - que teve uma grande expansão nos períodos das greves dos/as docentes do Centro Universitário Metodista - IPA - que compõe o movimento estudantil do qual decidi escrever. A proposta é a seguinte: uma peça teatral; não necessariamente uma peça teatral em seu modelo, mas uma criação referenciada em uma escrita teatral. Aliás, como a escrita também faz parte desse processo criativo, é bem possível que a proposta não aconteça exatamente dentro dos moldes do que se espera de uma peça teatral, afinal de contas, não estipulei moldes, assim como o movimento estudantil dentro do IPA não o fez. 0 texto será composto em três atos, parecido como uma peça de teatro. Em cada ato temos as cenas, e em cada cena temos pausas, onde algumas personagens dialogam mais diretamente com quem está lendo. Mesmo assim, sinta-se à vontade para conversar com o texto em qualquer momento.

Ora, nesse momento, convido-te a ler esse texto deixando-se levar pela história que é vivida ao ler, que foi vivida ao cartografar e que se viveu durante as cenas, sim, com todos esses atravessamentos. É importante lembrar que o texto é atravessado por elementos virtuais e suas atualizações, denotando a presença do plano da imanência durante todo processo de escrita. Aqui entendemos esses termos a partir da ideia de que

"O presente é um dado variável medido por um tempo contínuo, ou seja, por um movimento que se supõe em uma única direção: o presente passa à medida que esse tempo se esgota. É o presente que passa, que define o atual. Mas o virtual aparece, por seu lado, em um tempo menor do que aquele que mede 0 mínimo de movimento em uma direção única. Por isso o virtual é "efêmero". (Deleuze \& Parnet, 1998)

Ainda assim, faz sentido retomar a importância da experimentação da leitura. Justamente porque esse trabalho não se propõe a ter um início, um meio e um fim; não tem a intenção de trazer uma conclusão e muito menos explicações e convicções sobre o que se deu dentro do IPA no primeiro semestre de 2018. A esse texto importa o entre, o meio, a duração, e perceba, tudo isso faz parte desse rizoma, inclusive a tua leitura. Por isso, não fiques triste ou decepcionado/a: não haverá moral da história; muito menos respostas e/ou soluções ao final. 0 que há é o processo, incessante processo.
Meu convite é a ti, pessoa que me lê, saibas que a partir de agora, em certa medida, farás parte do movimento estudantil supracitado, e espero que consigas saborear as experimentações todas que serão cartografadas e mapeadas. Pronto, agora podemos começar.

\section{Primeiro ato}

\section{Os barulhos da multidão}

Cena 1- Estamos no campus central do Centro Universitário Metodista - IPA, bairro nobre de Porto Alegre - seja lá o que isso quer dizer. Um lugar silencioso e bonito, quanto mais na perspectiva da natureza: são muitas árvores, essas centenárias - assim como a Instituição elas compõem. Alguns prédios de arquitetura mais contemporânea e um grande prédio, aquele principal, o Prédio A (ele se parece muito com o Pantheon de Roma) e exatamente a sua frente, na sua saída principal, uma escadaria. Todos os caminhos do campus central levam ao Prédio A; ao se entrar pela entrada principal a primeira visagem é de muitas árvores, bancos e muitas calçadas que chegam até a escadaria do prédio (aos moldes europeus, essa distribuição lembra muito). É uma terça-feira letiva, final de tarde, a escadaria do Prédio A é ocupada por estudantes de todas idades, cursos e semestres possíveis. 0 plano de fundo é que os/as docentes dessa Instituição haviam começado a trazer à tona as situações que vinham acontecendo já há algum tempo. No dia anterior, segunda-feira, os/ as docentes em reunião no Sindicato decidiram pelo indicativo de greve. E 0 que acontece, é o que vamos chamar de Multidão (mais a frente na história entraremos nesse conceito de modo mais profundo).

(Ainda mais cedo, estudantes de cursos diferentes confeccionam cartazes que denunciam os problemas da instituição que estudam. Eum, em especial, bem grande e feito com um tecido, dizia a seguinte frase: "SE 0 IPA NÃO MUDAR, OS ESTUDANTES VÃO PARAR").

Pausa na cena, a árvore do canto começa a cochichar:

Os encontros narrados nessa cena dão conta de figurar três conceitos: Sociedade de Controle; Governamentalidade e Multidão. São três conceitos muito válidos para discussões que envolvem os movimentos sociais, pois importam-se em traçar reflexões que vão para além do plano macro, que colocam no debate aspectos sociológicos e filosóficos significativos para processos genealógicos e cartográficos.

(Volta a cena)

Havia algumas pequenas combinações - entre poucos/as estudantes - referentes a esse encontro. Estudantes e representantes de centros acadêmicos sentiram a responsabilidade de mostrarem suas incomodações quando souberam dos atrasos salariais dos/as docentes. Mesmo com essa combinação, o que não se esperava era a quantidade de pessoas juntas naquele lugar. 0 que causa comoção é também a presença do grupo de estudantes da Universidade do Adulto Maior (UAM), pessoas mais velhas que também estudam ali, com cartazes "GREVE ATÉ A VITÓRIA" e flautas fazendo barulho. Era quase 18h quando o cartaz, aquele maior, chega em frente ao prédio, todas pessoas ali aplaudem e gritam "é isso aí". Algumas pessoas puxam gritos de guerra "o professor é meu amigo, mexeu com ele, mexeu comigo"; "o IPA quer transparência", etc. A partir desse momento, cada pessoa que chega ao campus e vê aquela movimentação toda, junta-se, aplaude junto, emociona-se. Muitas pessoas ainda nem sabem o que está acontecendo, 
fazem interrupções e pedem explicação, nesse momento faz-se al gumas falas, explica-se al guns fatos e abre-se a passagem de uma ata para assinatura que mostra o descontentamento dos/as estudantes com sua instituição de ensino e em favor do movimento dos/as docentes. Ali mesmo decide-se em conjunto a proposta de todos/as fazerem uma caminhada que percorre todo um círculo em volta do Prédio A, e que se finda no centro do prédio C para falas. Agora tem-se instrumentos de bateria, gritos de guerra e uma Multidão.

Essa aglomeração toda faz rebater muitos sentimentos, uma intensidade tamanha e muito estranha (a cada um/a, ao IPA, e ao Prédio A).

As movimentações são cheias de olhares, toques e pensamentos que dizem: - Não sei o que está acontecendo exatamente, mas nem preciso saber por exato, os/as docentes sem receber seus salários e um indicativo de greve, fazem eu me movimentar.

(0 Prédio A sente, em suas escadas e com os sons que ecoam nas movimentações, as forças e as energias das pessoas que se juntam ali, são movimentos estranhos a ele. Um prédio, acostumado com o silêncio, com os passos apressados de estudantes atrasados para suas aulas, com as atividades administrativas e diplomáticas prestadas na Reitoria, na Coordenação de Graduação, no Auditório. Já vinha incomodando-se com al gumas mudanças, sobretudo ao curso de Música, que viera fazer parte de sua estrutura há mais ou menos um ano, trazendo sons e experiências diversas ao de costume, um espaço que estava sendo atravessado por acontecimentos que as linhas de segmentaridade dura de Deleuze e Parnet (1998) nada gostam.)

Pausa na cena, a árvore do outro canto começa a cochichar:

Ainda na segunda metade do século passado, Foucault (1999) analisara a sociedade da opacidade do poder e transparência dos indivíduos: a Sociedade Disciplinar. Onde esses indivíduos estão sendo observados pelas instituições totais a todo momento (como a imagem do Panóptico) com as punições prontas a serem aplicadas caso alguém desobedeça: a sociedade da obediência e do enclausuramento em sua magnitude. Os processos disciplinares se aplicavam para todas instituiç̧ões (família, escola, fábrica, hospital, prisão, etc), em que os sujeitos são constituídos corpos dóceis de Foucault (1993), onde se sabe exatamente quem o governa e quem o pune.

Entretanto, é perceptível que não se vive mais uma sociedade inteiramente disciplinar, assim como afirma Deleuze (1992) "Encontramo-nos numa crise generalizada de todos os meios de confinamento, prisão, hospital, fábrica, escola, família. [...]. São as sociedades de controle que estão substituindo as sociedades disciplinares" (p.1). Nesse caso, pode-se perceber algumas diferenças entre essas Sociedades quando nas sociedades de controle a governamentalidade se dissipa em múltiplas instâncias e já não se sabe ao certo quem governa.

Costa (2004) quando fala sobre Sociedade de Controle reitera que "[0] poder hoje seria cada vez mais ilocalizável, porque disseminado entre os nós das redes. Sua ação não seria mais vertical, como anteriormente, mas horizontal e impessoal" (p. 2). Essas transformações configuram novos modos de vida do sujeito contemporâneo, assim como os seus processos de subjetivação, nesse sentido " [0] controle é de curto prazo e de rotação rápida, mas também contínuo e ilimitado, ao passo que a disciplina era de longa duração, infinita e descontínua. 0 homem não é mais o homem confinado, mas o homem endividado" (Deleuze, 1992, p. 3).

\section{(Volta a cena)}

Ao mesmo passo o Prédio A, enquanto a movimentação das pessoas faz por ele um círculo, ele observa com atenção como aquilo tudo não faz parte de sua instituição (até um pouco irritado), como alguém que diz: - Tem algo errado, tem algo muito errado. Isso não faz parte do meu funcionamento, não é assim que sou.

São muitas pessoas, todas elas gritam juntas, caminham pelo campus, seus corpos demonstram a intensidade e a mistura dos sentimentos, mas é quase impossivel encontrar palavras que alinhem uma explicação do que está acontecendo. Já as pessoas que observam a movimentação variam em reações, muitas sorriem (contentes com o que veem), outras desviam o olhar, algumas aplaudem, filmam, etc.

Pausa na cena, a árvore da frente do Prédio A começa a cochichar:

Ao pensar, portanto, nos movimentos sociais mais contemporâneos, percebe-se suas diferenças com relação às características dos movimentos sociais com longa trajetória. Nas últimas décadas os movimentos sociais tomaram forças diversas, com motivos profusos, objetivos múltiplos e os sentimentos plurais. Diferenciando-se dos movimentos do século passado, as ruas são tomadas por pessoas que nunca foram ligadas ao espaço público como lugar para reivindicar suas angústias políticas, pessoas que ocupam 0 mesmo espaço público de reivindicação, mas com demandas diferentes, esses "os novos movimentos sociais, a princípio, não incorporam utopias grandiosas de emancipação social que exijam clareza político ideológica" (Harvey et al., 2015, p.36). Essa diferenciação dos movimentos caracteriza as mudanças às necessidades de uma sociedade de controle.

(Volta a cena)

Mesmo com aula, quase todos/as alunos/as decidem ficar em frente ao prédio A, em suas escadarias, conversando e debatendo sobre as situações que estão aparecendo. A ata terminou a noite com mais de 300 assinaturas de estudantes. No dia seguinte, o início da greve dos/as docentes.

Última pausa na cena, a árvore do canto começa a cochichar:

É nesse contexto que o movimento estudantil do IPA expande suas forças. Dentro de uma instituição centenária, onde os movimentos sociais ainda não tinham sido realidade, os/as estudantes do primeiro semestre de 2018 experienciam as potências que se atravessam ali. 0 que acontece na cena apresenta "as singularidades, os coletivos de resistência, a multidão [...]", que aparecem como "processos aberrantes, monstruosos, difíceis de capturar" (Carvalho, 2016, p.13). São, portanto, as faíscas de potência que estalaram em todos/as que viveram aquela cena (inclusive, arrisco-me a dizer que essas faíscas ainda estalam).

Dessa forma, aos agenciamentos coletivos de enunciação de Deleuze e Parnet (1998), experiencia-se um lugar diferente. Um lugar que, para aquela duração foi Multidão, estranhou e estranhou-se, não quis se cristalizar.

A utopia que se entrevênesse tom a um só tempo cáustico e terno não configura um contorno geométrico acabado com cores de um outro mundo, mas apenas prolonga as linhas de força já presentes neste mundo, em um telos coletivo e experimental da multidão (Pelbart, 2002, p.3). 
Sendo assim, as intensidades inclassificáveis que são estranhadas pela instituição (e, na cena, também pelo Prédio A) são os barulhos da multidão que se espalharam pelo IPA. Esses barulhos, que "dessilenciam" 0 campus quieto, que amolecem a dureza da instituição, que desobedece a governamentalidade. Os barulhos da resistência, da desordem, da potência, do inclassificável, os barulhos da Multidão.

\section{Segundo ato}

\section{A militância alegre}

Cena 2 - Agora estamos no saguão dentro do Prédio A. Entre a Coordenadoria de Graduação e a Reitoria. Estudantes que se encontraram dentro do IPA poucos dias antes, agora compartilham quase todos os dias de greve juntos/as. Entre atos, falas, reuniões com diferentes autoridades, assembleias internas, entrevistas para jornais: os momentos de confecção de cartazes.

Esses momentos acontecem constantemente, haja visto a reações da instituição em sempre arrancarem os cartazes colados pelos/as estudantes no campus. Assim como mágica, menos de uma hora depois que os/as alunos/ as colam os cartazes, eles desaparecem.

Pausa na cena, a árvore do canto volta a cochichar:

Quando pensamos no modo dialético, platônico e cartesiano que funciona nas sociedades historicamente e contemporaneamente, percebemos os afetos sempre divididos do pensamento racional. A binariedade pertence ainda às divisões mente/corpo, razão/emoção, pensamentos/sensações, etc. Essas compreensões dão sustentação para os modelos e ideais platônicos que permanecem sempre nos modelos que se deve tentar buscar, embora se saiba também que os modelos são inalcançáveis. Esses modos transcendentes de funcionamento da vida estão presentes desde a época de Platão até hoje, muito estratificados nos modos de subjetivação atuais. Dessa forma, é possível entender os afetos e as relações mais sensíveis ao corpo (sem diferenciação e/ou divisão mente-corpo) foram, e em certa medida ainda são, excluídos dos movimentos de luta.

\section{(Volta a cena.)}

Outra pausa, essa dramática, na cena. Os bancos da frente do Prédio A começam a conversar entre si:

\section{Banco 1 - 0 Prédio A é - também - a imagem do IPA.}

Banco 2 - É também o primeiro e mais importante prédio do IPA, nele fica instalada a Reitoria, a Coordenadoria de Graduação e o maior Auditório da instituição.

Banco 3 - Não podemos esquecer que a instituição foi crescendo em volta do Prédio A, fisicamente e subjetivamente.

Banco 2 - Sim, o Prédio A é quem vive o IPA desde o seu nascimento.

Banco 1 - 0 Prédio A é essa incessante reiteração e construção de linhas de segmentaridade dura (não à toa a escrita e a leitura dessa parte da história parece ser tão endurecida, frases curtas e cheia de pontos finais). 0 Prédio $\mathrm{A}$ vê tudo que acontece no IPA, o tempo inteiro (ou, pelo menos, parece ser 0 tempo inteiro para aqueles que ficam no entorno dele, não há como verificar se essa observação é constante.
Banco 3 - Sob um olhar do plano macro, acontece assim como o Panóptico de Foucault (1993). Entretanto, ele não se basta a esse aspecto, ainda que disciplinar, o Prédio A se dissolveu à tecnologias e mecanismos de controle por todo o IPA. Nós sentimos isso. Eisso denota a ele, portanto, dispositivos capazes de construir muros institucionais invisíveis por todo campus, tentando fazer funcionar tudo dentro da ordem, tudo sob controle - pelo menos quase tudo.

Banco 2 - Ele já vem há algum tempo incomodando-se com a questão do curso de Música que foi realocado de outro campus para dentro do Prédio A, lembram?

Banco 1 - Sim, o prédio mais silencioso do campus central recebe um dos cursos mais barulhentos. Se a gente se incomoda aqui de "fora", imaginem para ele.

(Feita a pausa. Voltamos para o saguão do Prédio A.)

Aliás, ele que já desconfortável com os sons constantes do curso de música, desde aquela terça-feira com os barulhos da multidão, vêm percebendo fortes sensações. As intensidades das emoções que acontecem no dia a dia durante uma paralisação de docentes (consequentemente das aulas) além de inesperadas, são surpreendentes. 0 campus central do IPA foi ocupado de maneiras novas e inusitadas. Para além da sala de aula, do Auditório, do Centro de Atendimento ao Aluno, da Biblioteca, do refeitório, o IPA estava sendo utilizado de maneiras novas. 0 que era uma escadaria, transformou-se em uma grande sala de assembleias e principal ponto de encontro entre os/ as estudantes.

Isso tudo incomodava bastante o Prédio A, é como se ele fosse, a todo momento, questionado de suas funções e de sua identidade. Para ele, alunos/as deveriam estar em suas salas de aula ou esperando pelas aulas. Se não havia aula, não haveria de ter estudantes, muito menos estudantes que estavam ali para questioná-lo, com olhares atentos às falhas. Como se, aos poucos, os estudantes furassem delicadamente os dutos do Prédio, causando pequenas infiltrações.

\section{Pausa na cena, a árvore da frente cochicha:}

Não obstante, para falar de resistência, dentro da perspectiva não binária nem de oposição, é preciso entender também o poder como algo relacional, implicado em uma grande rede de relações que se transversalizam. 0 convite é para entender as relações de poder como parte importante na compreensão sobre as imbricações das resistências em movimentos sociais. Ao passo que os processos foram tomando caminhos binários, o próprio movimento foi resistindo também a isso, Foucault (1988) reflete sobre isso quando diz"onde há poder, há resistência" (p. 91). Nesse sentido, ainda parece ser importante destacar o modo como Foucault (1988) compõe resistências e relações de poder:

[...] não existe, com respeito ao poder, um lugar da grande Recusa — alma da revolta, foco de todas as rebeliões, lei pura do revolucionário. Mas sim resistências, no plural, que são casos únicos: possíveis, necessárias, improváveis, espontâneas, selvagens, solitárias, planejadas, arrastadas, violentas, irreconciliáveis, prontas ao compromisso, interessadas ou fadadas ao sacrifício; por definição, não podem existir a não ser no campo estratégico das relações de poder (Foucault, 1988, p. 91). 
Resistências, portanto, configuram-se como irregulares, transitórias e móveis provocando rompimentos e transformações na sociedade em composição com as relações de poder implicadas nesses processos. Ainda que pontos de resistência possam causar rupturas maciças, radicais e binárias em alguns momentos, é mais corrente os movimentos micro políticos e de clivagem nos modos de ser (Foucault, 1988, p. 92). Nesse sentido, ainda que em atividades como confecção de cartazes, o movimento estudantil do IPA estava resistindo, e as percepções acabam por se tornar mais sensíveis aos acontecimentos corriqueiros, aos processos menores que fazem vazar as singularidades, as dissonâncias e os devires.

(Volta a cena)

E voltamos para a confecção de cartazes dentro do saguão do Prédio A. Esses momentos são cheios de Afetos Alegres de Spinoza (2009), momentos de intensidades tantas que abrem espaço para os encontros, esses que produzem desterritorialização, potência de agir. 0 que diferencia afetos tristes de afetos alegres é a correspondência com a vontade de potência ea potência de agir. Ao passo que os afetos tristes estabilizam e paralisam as intensidades e as mudanças, os afetos alegres provocam movimentações importantes, que desconfiguram os processos já dados e potencializa transformações. $A$ movimentação que esses Afetos Alegres disparam em cada corpo que está ali é, sobretudo, fruto da intensidade dos encontros.

Conversas incessantes, sobre tudo que se pode imaginar: papos sobre as situações do IPA; a vida de cada um/a; os cursos; sobre Política. Os/as estudantes, enquanto escrevem e pintam os cartazes, debatem política (da mais complexa a mais simples) dando risadas. São risadas de potência, de afetos que engrandecem a luta de cada um/a, assim como expandem as forças do movimento estudantil. São encontros afetuosos, em que estão presentes pessoas que querem estar ali, que sem obrigação al guma com provas ou notas, estão ali pela vontade de resistência. Pelo desejo de compartilhar momentos de transformação; pela intensidade dos afetos.

Pausa da cena, a árvore do outro canto volta a cochichar:

Mesmo que essas noções já tenham se dissipado com as implicações da sociedade de controle na contemporaneidade, ainda se percebe as incomodações com andamentos sensíveis a corpo, ainda se busca meios pragmáticos de resolução. 0 que se esquece ou não se enxerga, porém, é a força do desejo nos processos de luta, é dos sentimentos e sensações mais variados que a potência, a resistência e as linhas fuga são construídas. Tomando os conceitos de Resistência, Relações de Poder e Linhas de Fuga, torna-se visível a importância dos afetos na construção de quaisquer mudanças sociais.

Ainda assim, é de suma importância a compreensão de Afeto para Spinoza (2009) como "as afecções do corpo, pelas quais sua potência de agir é aumentada ou diminuída, estimulada ou refreada, e, ao mesmo tempo, as ideias dessas afecções" (p. 25), em que a noção de divisão mente/corpo não está presente. Além disso, porque Spinoza traz para os afetos a força e a potência que têm. Justamente por tecer novos olhares sobre o que são as transformações sociais, entendendo, assim, as mudanças nos processos micro políticos.

\section{(Volta a cena)}

Os/as estudantes, ainda nos momentos de confecção de cartazes sentem-se subversivos. Percebem que o que conversam, o que falam e o que fazem, mesmo que em momentos micro, transformam aquele lugar. Alguns até pedem cuidado para o que falar, pois "as paredes escutam". Realmente, 0
Prédio A ouvia tudo, e percebia as transformações. Eram as Linhas de Fuga que consistem em processos de resistência a partir da noção de devir, em que não há nada dado a priori. Linhas que quebram tanto com a delimitação de uma identidade, quanto com os modelos dialéticos. Nesse caso, são processos que perfuram as desconstroem a concretude de uma molaridade que limita e reduz os modos de ser/estar. "Há linhas que não se reduzem ao trajeto de um ponto, e escapam da estrutura, linhas de fuga, devires, sem futuro nem passado, sem memória, que resistem à máquina binária" (Deleuze \& Parnet, 1998, p. 22) - se infiltrando e causando pequenas rachaduras nas fortes e duras estruturas do Prédio $A$.

Pausa na cena, a árvore da frente cochicha:

Concomitante a esses enlaces, podemos procurar observar e salientar os processos de Linhas de Fuga a partir do entendimento de Deleuze e Parnet (1998) "[s] obre as linhas de fuga, só pode haver uma coisa, a experimentação-vida" (p.39). Dessa forma, evidencia-se as singularidades presentes nesse espaço - dadas por Foucault como resistência - também como Linhas de Fuga, pois" [...] as singularidades não se deixam totalizar, capturar, instituir. Fogem, escapam - tal como água por entre dedos - à norma e a seu ideal totalizante. Portanto, as singularidades são, em si mesmas, modos de resistências" (Benevides et al., 2011, p.34). Nesse sentido, podemos incorporar os movimentos sociais de luta por minorias, e nesse caso o movimento estudantil do IPA na discussão, visto que nesses espaços observa-se as linhas de fuga diariamente, pensando ainda que "[u]ma minoria nunca existe pronta, ela só se constitui sobre linhas de fuga que são tanto maneiras de avançar quanto de atacar" (Deleuze \& Parnet, 1998, p. 36).

É nesse contexto que voltamos a refletir sobre os afetos e os encontros que acontecem na cena. Para Foucault (1991) "[n]ão imagine que precise ser triste para ser militante, mesmo se a coisa que combatemos é abominável. É o elo do desejo à realidade (e não sua fuga nas formas de representação) que possui uma força revolucionária" (p. 3), esse entendimento diz respeito aos processos dos/as estudantes do movimento estudantil do IPA. A cada conversa, risada e construção de intimidades compunha-se os encontros, os afetos alegres, as potências.

Cena 3- Estamos na escadaria do Prédio A, em uma assembleia. Estamos também em um grupo deWhatsapp. Estamos em pequenas reuniões internas no refeitório. 0 movimento estudantil começa a ter alguns processos um pouco diferente daqueles da cena anterior. Tentativas feitas por estudantes, professores, igreja e etc. de delimitar o movimento.

Intenções que dizem -"Pessoal que estiver disposto a estar no grupo, que falem o mais rápido possível. Se não é melhor deixar o movimento, precisamos de qualidade, não de quantidade".

Pessoas mais velhas que dizem - "Vocês precisam retomar as atividades do DCE, vocês precisam fazer desse jeito, pois eu participei de movimentos estudantis há muito tempo, é assim que funciona. Vocês só vão conseguir tirar essa reitoria assim".

São muitas vozes que dizem como o movimento deve ser, como ele deve funcionar, o que ele deve fazer. Sempre baseados em objetivos fixos e históricos concretos. Pouca margem de erro, muito contorno e planejamento. E o que mais assusta: não corresponde majoritariamente pelas múltiplas ideias de todos/as do movimento.

Pausa na cena, a árvore do canto cochicha: 
Pensando agora nas tentativas de delimitação e identificação do movimento estudantil, seus processos duros e pragmáticos, Foucault (1991) faz uma importante pergunta quando toma o seguinte:

Como fazer para não se tornar fascista mesmo quando (sobretudo quando) se acredita ser um militante revolucionário? Como liberar nosso discurso e nossos atos, nossos corações e nossos prazeres do fascismo? Como expulsar o fascismo que está incrustado em nosso comportamento? (Foucault, 1991, p. 3).

A reflexão que podemos fazer aqui é sobre a presença dos microfascismos dentro de um movimento de luta, especialmente nesse. As formas como os microfascismos aparecem dentro do movimento estudantil do IPA correspondem as dificuldades que o movimento vai apresentando de "se mostrar eficaz", ou as capturas que vai aderindo na tentativa de se igualar ao que se entende - por uma via molar - por movimento social. Nesse sentido, retoma-se a noção de que os microfascismos estão no campo social sem precisar pertencer a um aparelho de Estado único. Além disso, de que por mais que um movimento social tenha saído do campo da segmentaridade dura, ocupando a linha flexível, ele continua em um regime ainda regulado (Deleuze \& Parnet, 1998). Onde há possibilidade do buraco negro em que podem aparecer "os Stálins de pequenos grupos, os justiceiros de bairro, os microfascismos de bandos" (Deleuze \& Parnet, 1998, p.113).

(Volta a cena)

0 pragmatismo em sua magnitude, buscando assim como diz um aluno - "coisas efetivas que sejam plausíveis".

0 Ressentimento e os Ideais Ascéticos de Nietzsche (2009) como montante de força tentando combater qualquer tipo de diferença que apareça durante o movimento estudantil. Agindo em busca da grande transformação, sem perceber as transformações que já estavam acontecendo, ou se percebendo, não validando como aquele objetivo a ser alcançado.

0 que acontece é que o movimento estudantil vem também em processos singulares e imanentes. E os atravessamentos identitários e restritivos são, em alguma medida, abafados. A multiplicidade do movimento responde a esses atravessamentos com a classe e a ponderação de quem examina com cuidado as Relações de Poder envolvidas. Essas como Foucault (1988) afirma:

"Que o poder não é algo que se adquira, arrebate ou compartilhe, algo que se guarde ou deixe escapar; o poder se exerce a partir de inúmeros pontos e em meio a relações desiguais e móveis; que as relações de poder não se encontram em posição de exterioridade com respeito a outros tipos de relações (processos econômicos, relações de conhecimentos, relações sexuais), mas Ihes são imanentes; são os efeitos imediatos das partilhas, desigualdade e desequilíbrios que se produzem nas mesmas e, reciprocamente, são as condições internas destas diferenciações; as relações de poder não estão em posição de superestrutura, com um simples papel de proibição ou de recondução; possuem, lá onde atuam, um papel diretamente produtor." (Foucault, 1988, p. 89)

Nesse sentido, a multiplicidade também busca, com criatividade e inventividade fazer fugir às capturas dos mecanismos de controle que o Prédio A construiu e segue reconstruindo junto com a sociedade contemporânea.

Pausa na cena, a árvore do outro canto cochicha:

Percebe-se também a intensa presença dos processos de experimentação, de diferenciação, de resistências. Muito em consonância com os movimentos de luta da contemporaneidade, o movimento estudantil do IPA encontra na multiplicidade, nos afetos e nas criações a força e a potência para construir novos modos de lutar. Assim como afirma Pelbart (2002):

Trata-se de construir, no não-lugar que as desconstruções das últimas décadas deixaram, um lugar novo. A partir da sinergia da multidão, tecer ontologicamente novas determinações do humano, de vida. Daí a nova imagem do militante na era pós-moderna, diante da dissolução da figura do povo. 0 militante não "representa" ninguém, e ao lado dos que se revoltam contra o reino do capital, ele resiste de maneira criativa, investindo dispositivos cooperativos de produção e de comunidade a partir de dentro do Império (não há como colocar-se"fora"dele). (Pelbart, 2002, p.3)

Desse modo, as infiltrações provocadas no Prédio A (nosso personagem principal), compõem os processos de Linhas de Fuga. Não mais com reações, atitudes binárias e de oposição, sem se preocupar em derrubar todo o Prédio $A$, o movimento estudantil, por caminhos criativos e afetivos, causa infiltrações, transformando boa parte do funcionamento do Prédio $A$.

Ademais, Pelbart (2002) ainda nos lembra que"Ao retomar as virtudes da ação insurrecional de dois séculos de experiência subversiva, [...], o militante atual é chamado a ir além, e a participar vitalmente na cooperação produtiva da intelectualidade de massa e das redes afetivas" (p.3). 0 militante agora é convocado a inventar modos de lutar que produzam desterritorialização, que busquem afetos alegres e a potência de agir. Essa perspectiva nos lembra as possibilidades de um cenário atual, onde há de existir uma militância alegre, essa que resiste com criação, invenção, que investe nos encontros e possibilita aos afetos a capacidade de transformação.

\section{Terceiro ato}

\section{A revolução do processo: a expansão do rizoma}

Cena 4 - Estamos em uma assembleia geral, dentro do auditório do Prédio A. É como se estivéssemos no coração do Prédio. Juntos/as: professores e estudantes. Duas reuniões aconteceram pouco tempo antes, um/a dos/as coordenadores/as de curso e outra dos/as representantes de estudantes, as duas com o que o Prédio A teimava em dizer que tinha a culpa da situação. Os/as estudantes já haviam percebido que encontrar culpados não era interessante, até porque se percebeu que não há culpado, existem muitos atravessamentos e agenciamentos para que o IPA chegasse a essas situações. 
Mesmo assim, os/as estudantes vão a essa reunião entrando em um espaço de luta. E lutam bravamente: escutam, falam, emocionam-se ao expressar todas as situações que haviam vivido nos últimos dias e tudo que percebem do lugar que estudam. Sabem a importância daquelas falas, que elas são tão valorosas quanto aquelas que se conversava durante as produções de cartazes. Que as mudanças estão acontecendo a todo momento, e aquele era mais um desses momentos, embora fosse um dos mais significativos. Como todos processos singulares de cada momento de luta, os/as estudantes compõem e constroem, do lugar onde estão, resistências.

Pausa na cena. A árvore do canto direito do Prédio A cochicha:

Sob um olhar historiográfico, estuda-se as revoluções a partir das grandes conquistas, grandes transformações, das grandes verdades. São momentos de muita importância e qualificam as fases da história. Entretanto, aqui estamos olhando por um olhar cartográfico. Aqui percebemos e mapeamos os processos de subjetivação de cada um/a. 0 olhar sensível da cartografia funciona " [...] como estratégia de análise crítica e ação política, olhar crítico que acompanha e descreve relações, trajetórias, formações rizomáticas, a composição de dispositivos, apontando linhas de fuga, ruptura e resistência." (Prado \& Tite, 2013, p. 3). Para cada estudante presente na reunião, havia uma reunião diferente, os sentimentos múltiplos. Para alguns a sensação de estar em um momento histórico era prevalente, para outros a vontade de estar ali era na mesma intensidade da vontade de estar junto com os/as colegas produzindo cartazes.

\section{(Volta a cena)}

A reunião acontece em outro lugar, que não o campus central. 0 caminho até lá foi feito a pé, estudantes juntos/as (com todas forças de cada um/a), conversando sobre, entre tantas vontades, as de potência. A reunião acontece devagar, os/as estudantes não estipularam hora para acabar. Ouvem com calma o que se diz a eles/as, e falam com a força de quem grita num palanque, num tom sutil e sincero. A vermelhidão no rosto denota as intensidades dos sentimentos vividos ali. A angústia de encontrar-se, cara a cara, com a certeza de que nada ali vai mudar radicalmente, vai transformar-se no modelo ideal que se deseja. Junto com a angústia, há também potência de sentir que as transformações são feitas todos os dias, que as resistências podem estar em todos espaços. Que tudo que foi feito ali naquela reunião, não fica somente ali, tem reverberações em tantos lugares. Ao saírem da reunião, caminham de volta até 0 campus central, lá voltamos para o Auditório do Prédio A.

Alguns/mas estudantes dizem: - A gente sabia que não ia ser fácil. Sabíamos que íamos encarar toda essa dureza, as frases prontas, as explicações rasas como regimes de verdade. Mas a gente também deu nosso recado, e isso borbulha, faísca e respinga por tudo que é canto.

Esses/as estudantes voltavam ao campus central com um misto de sentimentos. Com aquilo que os/as historiadores/as chamam de "cabeça erguida", e aquilo que, aqui, chamamos de afetos alegres. Percebem que fizeram fugir aquilo que mais aprisionava e endurecia os processos todos nos últimos tempos no IPA.

Pausa na cena. Árvore do canto esquerdo do Prédio A percebe a chegada dos/as estudantes de volta ao campus central e cochicha:

Os/as estudantes percebem que combatem não só os leões das grandes verdades, das estratificações mais duras. Constroem processos de minoração potentes, que perfuram os mecanismos mais sólidos, as rochas mais maciças.
E, além disso, também desconstroem as linhas flexíveis, que relativizam alguns modos à custa de outras formas corretas, nesse caso, de lutar. Eis aqui o que chamamos de processos de minoração. Compondo com as linhas de fuga, traçadas nesses espaços, "[...] com o"minorar" (termo empregado pelos matemáticos), com o impor um tratamento menor ou de minoração, para liberar devires contra a História, vidas contra a cultura, pensamentos contra a doutrina, graças ou desgraças contra o dogma" (Deleuze, 2010, p. 36). Tornar menor é, também, abrir possibilidade para o devir. Afetar e se deixar ser afetado/a. Olhar para essas intensidades é resistir junto com elas, contra os modelos (tão reducionistas), é inventar novos modos de lutar, dar força para aquilo tudo que nos potencializa, sem ignorar o que já se faz.

Se houve um momento onde podíamos apontar um inimigo, a repressão, o controle; este tempo não é o nosso. Um poder sobre a vida atravessa o nosso corpo, nossos afetos, nossa sensibilidade de uma maneira violenta e perspicaz. Não se trata de uma ideologia a combater, como se o poder fosse externo e sujeito maciço, trata-se de percebermos os entrelaçamentos entre as capturas em que nos constituímos e os processos singulares que escapam continuamente, por onde nos inventamos. Em nós, nos grupos, nos movimentos, nas instituições, na política (macroe micropolíticas); de maneira a inventar outras zonas de criação que suportem por algum tempo a raridade que portam, a novidade que abre picada no mundo (Amarante, 2016, p. 1277).

São a partir dessas experimentações que os/as estudantes construíram e constroem, dia após dia, meios minoritários de lutar. Quando negam serem representados/as por entidades, mas também quando valorizam e acreditam nos sentimentos. Quando não aceitam respostas prontas, mas também quando enunciam os problemas sem serem cooptados pelos modos binários e polarizados de resistir.

Cena 5 - Chegam os/as estudantes ao Auditório do Prédio A novamente, uma noite de segunda-feira. Professores/as seguem sem receber seus salários. Os/as alunos/as entram naquele espaço centenário, com centenas de pessoas, estudantes e professores/as. A sensação é a de que ali está se comemorando uma conquista muito significativa. A reitoria havia caído. Alguns comemoravam muito, como se isso transformasse tudo. Os/as estudantes que vieram da reunião já sabiam disso, sabiam de tantas outras questões também. Muitas dessas questões que os deixavam sem essa sensação de vitória e resolução, sobretudo porque o movimento estudantil não tinha tantos objetivos específicos, nem mesmo a vontade de derrubar a reitoria. Essa situação é só mais uma cena do processo incessante de luta.

Os/as docentes abrem um espaço de fala para os/as estudantes no final de suas colocações. 0 Auditório do Prédio A lotado de pessoas.

(0 Prédio A sente um embrulho no estômago cada vez que há palmas, vozes e emoções sendo expressadas.)

As falas que sucedem depois dos/as professores/as são fortes. Estudantes que sentem todas as movimentações do IPA de diferentes formas das dos/as docentes. Contam ali sobre a reunião, sobre os últimos dias, sobre as tantas 
outras reuniões, sobre as assembleias internas, a importância da participação de todos/as, sobre as perspectivas que sentem no panorama atual.

As falas são intensas, são revolucionárias, assim como cada dia e encontro que se deu naquele lugar nos últimos tempos. Os devires-revolucionários que aconteceram ali não podem ser contados em palavras, mas foram vividos, inclusive em partes daquela noite.

Pausa na cena. Árvore da frente do Prédio A pede licença para falar:

Um devir-revolucionário permanece indiferente às questões de um futuro e de um passado da revolução; ele passa entre os dois. Todo devir é um bloco de coexistência. (Deleuze \& Guattari, 1997, p. 78)

Podemos refletir sobre o devir-revolucionário como o processo de minoração necessário para se fazer política. 0 que significa, então, entender que esses meios de minoração acontecem em devires diversos, mas sempre em consonância com movimentos singulares e incertos pois" [e]sses devires dizem respeito ao devir revolucionário da multidão, os processos que os movimentos constroem, sua riqueza atual e não o projeto futuro que acompanha as lutas" (Carvalho, 2016, p. 11). Além disso, percebe-se a intensa necessidade de afirmar o processo como transformador, Deleuze $(2010$, p. 34) deixa claro quando retoma:

\section{0 interessante nunca é a maneira pela qual alguém começa} ou termina. 0 interessante é o meio, o que se passa no meio. Não é por acaso que a maior velocidade está no meio. As pessoas sonham frequentemente em começar ou recomeçar do zero; e também têm medo do lugar aonde vão chegar, de seu ponto de queda. Pensam em termos de futuro ou de passado, mas o passado, e até mesmo o futuro, é história. 0 que conta, ao contrário, é 0 devir: devir-revolucionário, e não o futuro ou o passado da revolução. "Não chegarei a lugar nenhum, não quero chegar a lugar nenhum. Não há chegadas. Não me interessa aonde uma pessoa chega. (Deleuze, 2010, p. 34).

Essa, portanto, éa revolução do processo, onde se observa, se valoriza e se destacam os caminhos dos afetos e dos devires que ressoam nos encontros das linhas de fuga, das resistências, das clivagens e das desestratificações dos sistemas molares. Não é preciso que saiam milhões de pessoas na rua bradar palavras de ordem para que isso seja considerado revolução. Há o devir-revolucionário antes mesmo de grandes rupturas e mudanças serem noticiadas ou percebidas empiricamente, há resistência antes mesmo de projetos conservadores serem aprovados. Entendendo que não se fala aqui das grandes verdades, mas sim das intensidades registradas em cada corpo, que se desterritorializa nos encontros múltiplos e sem ideais.

Quando se olha para os devires-revolucionários, entende-se que não há um jeito certo de fazer revolução, que esse processo não está dado a priori, portanto, dá-se no que se passa no meio, no durante, no processo, naquilo que não está delimitado. As resistências, as linhas de fuga, os devires revolucionários são provocados por intensidades não documentadas nem em livros de história nem em jornais, essas intensidades são documentadas por aqueles/as que vivem movimentos sociais (seja ele qual for, dentro de sua casa, de uma sala de aula, espaço de trabalho, etc) entendendo que é no processo que se dão as mudanças.

(Volta a cena)

Alunos/as que provocam questionamentos a todas pessoas que estão ali, levando as incomodações de seus corpos a diferentes corpos, de diferentes formas. As forças que se transversalizam ali não podem nem querem ser documentadas, não há limitações para os alcances.

São vozes diversas, incomodações múltiplas, os Barulhos da Multidão voltam, de modos diferentes, em um lugar diferente e com pessoas diferentes. Diferentes pela duração de tempo que se viveu. É o IPA, o Prédio A, os/as docentes, os/as estudantes, os mesmos de mais ou menos um mês atrás. As mesmas identidades, mas não as mesmas pessoas. As transformações são constantes, sobretudo num processo de luta. Há ali pessoas que participaram de variadas formas do movimento estudantil, al gumas estavam todos os dias no Prédio A, outras estavam em alguns momentos, muitas participaram dos atos. Há ali também pessoas que acompanharam de longe todos os acontecimentos, preocupadas com tudo que poderia acontecer e apoiando os/as colegas que estavam mais próximos de tudo. E também há as pessoas que não concordavam com movimento estudantil.

Todos esses atravessamentos bombeavam aquela noite com forças diferentes. Desde algum tempo, que não se sabe nomear, em algumas pessoas crescia um tipo de caule. Devagar e pequeno no início, crescia com cada reflexão feita, com cada conversa, momento, aula, reunião. Expandia em si e no IPA um caule que cresce horizontalmente. Que transforma, cotidianamente, um pouquinho de cada um/a que por ali vive. Esse caule se chama Rizoma.

Pausa na cena. Árvore do canto direito volta a cochichar:

Parece pertinente tomar o conceito de Rizoma logo nesse momento. Entretanto, há necessidade de contar sobre essa sensação que eu e as outras árvores estamos sentindo ultimamente. Esse tal de Rizoma está chegando em nós, e também no Prédio A. 0 Prédio A tem reclamado há algum tempo dessas mudanças, talvez fosse o Rizoma já se mostrando subterraneamente. Enquanto falo contigo, sinto que faço novas reflexões, talvez seja esse sistema, que por estar sempre aberto e sem limitações, faça com que eu possibilite novas formas de ser/estar no mundo. Talvez essa sensação já tenhas sentido também, ao acompanhar essa leitura. Giordani (2016) refere-se a essa sensação:

[...] texto não é pessoal, não trata de uma história que 0 escritor viveu. Traz para o texto escritos que estão abertos, que pedem para o leitor os terminar; que possibilitam a entrada do leitor e, assim, o texto passa a ser uma co-produção; uma produção entre leitor e escritor, ambos escrevendo o texto em tempos diferentes. (Giordani, 2016, p. 10)

Sendo assim, sinto que compartilhas comigo essa sensação, será que não? (Volta a cena)

Esse Rizoma vem se expandindo, não há como saber desde quando (nem há essa intenção). Ele vai crescendo pelo campus sem que se perceba 
a olho nu. Ainda dentro do auditório, os/as estudantes percebem esse caule fazendo desenhos novos por toda estrutura do espaço; questionam-se como tudo aquilo tinha acontecido em tão pouco tempo, percebem que, provavelmente, estava acontecendo havia um tempo, e as sensações que vinham tendo eram esse caule crescendo. São linhas, "não existem pontos ou posições num rizoma como se encontra numa estrutura, numa árvore, numa raiz. Existem somente linhas." (Deleuze \& Guattari, 1995, p. 16), essas que passam quase despercebidas, não fosse as sensações que elas provocam. Sensações que desacomodam, não se sabe de onde vêm, para onde vão, nem porque estão passando por ali. Sabe-se como elas vão crescendo: as movimentações todas dessas cenas são motores dessa expansão.

As Árvores que cochicham, o Prédio A e os Bancos começam a sentir as linhas que percorrem, subterraneamente, o campus central do IPA. 0 Rizoma se alastra sem direção ou objetivo, crescendo para todos os lados, atravessando-se. Perfurando alguns modos endurecidos, territorializando-se em outros. As linhas se diferenciam entre si, são duras, flexíveis, de fuga: se entrelaçam e descompassam as institucionalizações do IPA. 0 Prédio A, sempre convicto de quem era, afetou-se; as Árvores que cochicham se vestiram de linhas; os Bancos tentaram dispor uma análise do que vinha acontecendo - eram as linhas duras -, compreenderam que pouco importava uma análise e foram interpelados pelas linhas flexíveis e de fuga. 0 Rizoma alcançou os/as estudantes, desenhou e desfez estarrecimento e potência, tudo nos corpos que ali caminham. Mexeu com as (falsas) estruturas, do IPA e dos/as estudantes, chegou até a autora dessas cenas, agora te encontra também. Bem percebido pelas Árvores que cochicham, não é mesmo?

Pausa na cena. Árvore da frente do Prédio A começa a falar em tom relativamente alto:

Ora, pois. Nos encontramos. Esse Rizoma fez com que nos encontrássemos e, nesse caso, a escrita com a tua leitura. A noção de Rizoma permeia um olhar sobre o mundo, as relações e acontecimentos, mesmo que não percebamos a todo momento, ele acontece. São esses emaranhados de linhas que nos constituem ao mesmo tempo que nos desconstroem. Que abrem possibilidade para o devir.

Um rizoma não começa nem conclui, ele se encontra sempre no meio, entre as coisas, inter-ser, intermezzo. A árvore é filiação, mas o rizoma é aliança, unicamente aliança. A árvore impõe 0 verbo "ser", mas o rizoma tem como tecido a conjunção"e...e...e..." Há nesta conjunção força suficiente para sacudir e desenraizar 0 verbo ser. (Deleuze \& Guattari, 1995, p. 36)

0 que aparece nessas cenas são as aberturas para a revolução, nesse caso, aos devires revolucionários. Éa compreensão empírica da valoração dos processos que potencializa as resistências e as desconhecidas formas de fazer revolução. Justamente porque, assim como afirma Deleuze (1974) "[0] devir não suporta a separação nem a distinção do antes e do depois, do passado e do futuro" (p.3). 0 que apresenta, dessa forma, a intensidade do meio, do processo; apresenta nos encontros minoritários a capacidade de revolução. Além disso, mostra a potência dessa noção quando entende o rizoma como um mapa, esse que "[é] aberto, é conectável em todas as suas dimensões, desmontável, reversível, suscetível de receber modificações constantemente. " (Deleuze \& Guattari, 1995, p.21).
Ainda assim, é possível pensar também da sutileza com que essas aberturas engrandecem os movimentos de luta, sobretudo o movimento estudantil do IPA. Percebemos encontros, diferença, onde "[n]ão há sujeito, mas agenciamentos coletivos de enunciação; não há especificidades, mas populações, música-escritura-ciências-audiovisual, com suas substituições, seus ecos, suas interferências de trabalho." (Deleuze \& Parnet, 1998, p. 23). Onde se possibilita os afetos, as desterritorializações. Um espaço múltiplo e, em alguns tantos momentos, sem delimitações da maneira certa de lutar.

0 Rizoma cresce e se expande, é sensível a diferentes maneiras de olhar, fazer e construir o movimento estudantil. Deleuze e Guattari (1995) notificam o que diferencia um rizoma, o comparando com um mapa, quando retomam:

Uma das características mais importantes do rizoma talvez seja a de ter sempre múltiplas entradas [...]. Um mapa tem múltiplas entradas contrariamente ao decalque que volta sempre "ao mesmo". Um mapa é uma questão de performance, enquanto que o decalque remete sempre a uma presumida "competência". (Deleuze; Guattari, 1995, p.21)

Nesse contexto, podemos compreender a dimensão da potência de um movimento que faz composições e abrem espaço para vivenciarem um rizoma. Não há a premissa de reprodução, nem mesmo de uma análise que codifica os modos de resistir e lutar. Essa seria uma lógica alinhada aos modos hierárquicos das reproduções, como uma árvore. (Deleuze \& Guattari, 1995, p. 20). Enquanto converso contigo, pessoa que faz essa leitura, confesso que me sinto atravessado por todas essas linhas. Assim como, talvez, tu te sintas também. Esses modos idealizados e reprodutivos com que cresci é também muito do modo como as pessoas constituem-se. Por isso a necessidade de desconstrução constante. Esse Rizoma, cartografado aqui em forma (bem desajustada e com poucas delimitações) de cenas, teve uma grande expansão na duração contada, mas segue se expandindo e crescendo nos encontros.

Ademais, são em todos esses encontros que aparecem as possibilidades que se abriram a partir do movimento estudantil, pois levam aos elementos virtuais implicados nessa composição. Essa que não pretende ter fim; que, com essas cenas encontra, em cada leitura, infinitas possibilidades. Quando Deleuze (1987) nos traz que"a arte é aquilo que resiste, mesmo que não seja a única coisa que resiste" (p.13), ele nos permite encontrar resistência, principalmente, na invenção. Invenção de uma estória, uma leitura, uma escrita, de um movimento de luta. Esse Rizoma que se expandiu e segue expandindo dentro e fora do IPA, cresceu também por essa escrita, pela tua leitura, chega aos teus olhos. Provoca movimento. Afeto. Provoca resistência. Revolução. A revolução do processo.

\section{Referências}

Amarante, A. H. (2016) 0 sujeito biopoliticamente correto e os personagens sem contorno. Anais [recurso eletrônico] do $5^{0}$ Colóquio Latino-Americano de Biopolítica, $3^{0}$ Colóquio Internacional de Biopolítica e Educação e 170 Simpósio Internacional IHU, São Leopoldo, p. 1275 - 1280, Casa Leiria.

Benevides, P \& Neto, J. (2011). Educação, subjetivação e resistência nas sociedades de controle. ECOS - Estudos Contemporâneos da Subjetividade, [S.L], v. v1, n. 1, p. 27-40. 
Bergson, H. (2006). Memória e vida. 1 ed. São Paulo: Martins Fontes. 184 p. Carvalho, D. (2016). Devir revolucionário da multidão: cartografia dos movimentos Okupae 15m. Tese (doutorado) - Universidade do Valedo Rio dos Sinos, Programa de Pós-Graduação em Ciências da Comunicação, São Leopoldo, RS, 215 p.

Costa, R. (2004). Sociedade de controle. São Paulo Perspec., São Paulo, v.18, n. 1, p. 161167.

Deleuze, G. (1974). A lógica do sentido. São Paulo: Perspectiva. 346 p.

Deleuze, G. (1992). Conversaçoes: Post-scriptum sobre as sociedades de controle. Rio de Janeiro: 34, 219-226 p.

Deleuze, G. (1987). Oa ato da criação. Edição brasileira: Folha de São Paulo, 1999. Deleuze, G. (2010). Sobre o teatro: Um manifesto de menos/o esgotado. 1 ed. Rio de Janeiro: ZAHAR. $111 \mathrm{p}$.

Deleuze, G. \& Guattari, F. (1997). Mil platôs. São Paulo: Editora 34, v.4.

Deleuze, G. \& Guattari, F. (1995). Mil platôs. São Paulo: Editora 34, v.1.

Deleuze, G \& Parnet, C. (1998). Diálogos. São Paulo: Escuta. 184 p.

Foucault, M. (1993). Vigiar e Punir. Petrópolis. Vozes. (Trad. port.; ed. orig.: 1975).

Foucault, M. (1991). Anti-Édipo: uma introdução à vida não-fascista. In: ESCOBAR, Carlos Henrique de (org.). Dossier Deleuze. Rio de Janeiro: Hólon, pp.83-84

Foucault, M. (1988). A história da sexualidade: a vontade de saber. 1.13 ed. Rio de Janeiro: GRAAL. $151 \mathrm{p}$.

Giordani, T. (2016). Nomadismo esociedade de controle: estudos sobre sobre os" malucos" em uma tese partida ao meio. Tese (doutorado) - Universidade Federal do Rio Grande do Sul, Programa de Pós-Graduação em Psicologia Social e Institucional, Porto Alegre, RS, 214 p.

Harvey, D., Teles, E., Sader, E., Alves, G., Carneiro, H. S., Wallerstein, I., ... Safatle, V. Occupy: movimentos de protesto que tomaram as ruas. (2015). 4 ed. São Paulo: Boitempo Editorial. 87 p.

Nietzsche, F. (2009). Genealogia da moral. 1 ed. São Paulo: Companhia das Letras. $176 \mathrm{p}$.

Pelbart, P. (2002). Império. Rev. adm. empres., São Paulo, v. 42, n. 4, p. 1-7.

Prado, K. \& Teti, M. (2013). A cartografia como método para as ciências humanas e sociais. Santa Cruz do Sul, n. 38, p. 45-49.

Spinoza, B. (2009). Ética. 1 ed. Belo Horizonte: Autêntica. 240 p. 